\title{
Molecular cloning and expression analyses of porcine MAP1LC3A in the granulosa cells of normal and miniature pig
}

Sang H Kim', Sue Y Hwang ${ }^{2}$, Kwan S Min ${ }^{2}$ and Jong T Yoon ${ }^{3^{*}}$

\begin{abstract}
Background: The members of the microtubule-associated protein 1 light chain (MAP1LC) family, especially those of the LC3 family (MAP1LC3A, B, C), are known to induce autophagy upon localization onto the autophagosomal membrane. In this regard, LC3 can be utilized as a marker for the formation of autophagosomes during the process of autophagy. The aims of this study are to clone porcine MAP1LC3A, and analyze the pattern of its expression in the ovarian tissues of normal and miniature pig ovary in an attempt to understand the distinct mode of apoptosis between two strains.
\end{abstract}

Methods: Rapid amplification of CDNA ends (RACE) were used to obtain the $5^{\prime}$ and $3^{\prime}$ ends of the porcine MAP1LC3A full length CDNA. Reverse-transcriptase-PCR (RT-PCR), real-time PCR, and western blot analysis were performed to examine the expression of porcine MAP1LC3A. The localization of MAP1LC3A in the ovary was determined by In situ Hybridization and Immunohistochemical staining.

Results: We cloned the full-length CDNA of porcine MAP1LC3A and identified an open reading frame of $980 \mathrm{bp}$ encoding 121 amino acids. Based on its homology to known mammalian proteins (98\%) this novel cDNA was designated as porcine MAP1LC3A and registered to the GenBank (Accession No. GU272221). We compared the expression of MAP1LC3A in the Graafian follicles of normal and miniature pigs by in situ hybridization at day 15 of the estrus cycle. While normal pigs showed a stronger expression of MAP1LC3A mRNA than miniature pigs in the theca cell area, the expression was lower in the granulosa cells. Immunofluorescence analysis of the MAP1LC3A fusion reporter protein showed the subcellular localization of porcine MAP1LC3A and ATG5 as a punctate pattern in the cytoplasm of porcine granulosa cells under stress conditions. In addition, the expressions of MAP1LC3A and ATG5 were higher in normal pigs than in miniature pigs both in the presence and absence of rapamycin.

Conclusions: The newly cloned porcine MAP1LC3A provides a novel autophagosomal marker in both normal and miniature pig. We demonstrated that the expression of MAP1LC3A in graafian follicle is distinct in normal and miniature pig, which may explain the unique folliculogenesis of miniature pigs.

Keywords: Autophagy, MAP1LC3A, Granulosa cell, Pig, Miniature pig

\section{Background}

Autophagy is a process of programmed cell death (PCD) through which damaged tissues and pathogens are removed. It is also involved in the degradation of abnormal proteins and in the remodeling of cells and tissues. With regard to this, cells are required to carry out an appropriate level of autophagy to maintain their survival as

\footnotetext{
* Correspondence: jtyoon@hknu.ac.kr

${ }^{3}$ Department of Animal Life Science, Hankyong National University, Ansung 456-749, Korea

Full list of author information is available at the end of the article
}

well as for intracellular homeostasis [1-3]. In particular, autophagy is closely associated with the remodeling of cells during the process of tissue formation [4]. A recent report suggested that apoptosis, probably through autophagy, promotes granulosa cells to form atresia in developing follicles [5]. The role of apoptosis during follicular development and atresia formation has been well studied in multi-ovulating mammals such as pigs; however, little is known about the possible involvement of autophagy in these processes [6,7]. In most mammals, autophagy is initiated by the suppression of the IGF-signaling pathway.

\section{Biomed Central}

(c) 2013 Kim et al.; licensee BioMed Central Ltd. This is an Open Access article distributed under the terms of the Creative Commons Attribution License (http://creativecommons.org/licenses/by/2.0), which permits unrestricted use, distribution, and reproduction in any medium, provided the original work is properly cited. 
The process of macroautophagy is also induced by rapamycin through the inhibition of mTOR activity [7]. In the course of autophagy, Beclin-1 first binds to Vps15 followed by the joining of ATG12-ATG5 and LC3 (ATG8), leading to the formation of a double-membrane structure called the autophagic vacuole $(\mathrm{AV}-1)$ [8-10]. This initial stage of the autophagosome includes some of the cytosol and the cellular organelles within it. Later, the AV-1 fuses with the lysosomes and develops into a single-membrane second-stage vacuole (AV-II) [11]. The formation of the mature autophagolysosome can be determined by the presence of the surface marker LC3. LC3 is a type of microtubule-associated protein (MAP), which is classified as MAP1LC3A, MAP1LC3B, or MAP1LC3C [12,13]. LC3 is further divided into LC3-I, which remains within the cell, and LC3-II, which binds to the phosphatidylethanolamine (PE) of the initial autophagosomal membrane [12]. LC-II remains in the membrane until the formation of the autophagolysosome [14,15], and thus can be utilized as a marker to determine the activity of autophagy. Mizushima et al. (2001) reported that the expression of LC-II is controlled by ATG5 another potential marker for detecting autophagy [16]. The genes encoding LC3 were cloned in a variety of mammalian species; however, its porcine homolog remains to be identified. In the present study, we determined the full-length nucleotide sequence of porcine MAP1LC3A cDNA by using mixed-base oligonucleotide primers designed based on previously cloned MAP1LC3A from other species. We also compared the expression of MAP1LC3A of granulosa cells in normal and miniature pig.

\section{Methods}

\section{Collection of porcine ovary tissue}

Ovaries were dissected from normal (Landrace, age: 10month, weight: $110 \pm 5.1 \mathrm{~kg}$ ) and miniature (Age: 10 month, weight: $26 \pm 2.1 \mathrm{~kg}$, Medi Kinetics co., Ltd; Pyeongteak, Korea) pigs were collected from gilts at a slaughterhouse (PyeongNong, Pyeongteak, Korea) and transported in physiological saline supplemented with penicillin G (100 U/ $\mathrm{ml})$ and streptomycin sulfate $(100 \mathrm{mg} / \mathrm{ml})$ at $37^{\circ} \mathrm{C}$, within 2 $\mathrm{h}$ to the laboratory. Treated ovaries were either kept in phosphate buffered saline (PBS) (for follicular cell extraction) or stored in liquid nitrogen for molecular analysis. This study was carried out in strict accordance with the recommendations laid out in the Guide for the Care and Use of Laboratory Animals of the National Institutes of Health. The protocol was approved by the Committee on the Ethics of Animal Experiments of the Hankyong National University (Permit Number: 2012-1).

\section{Granulosa cell culture}

Follicles were obtained from freshly isolated ovaries. Fluid from follicles (4-8 $\mathrm{mm}$ in diameter) was aspirated using an 18-gauge needle attached to a 5-ml disposable syringe. Follicular aspirates were kept at $37^{\circ} \mathrm{C}$ and allowed to sediment for $5 \mathrm{~min}$. The sediment was removed, and the remaining was allowed to sediment for a further 30 min, until pellets of aggregated granulosa cells with a uniform size range were created. The supernatant containing mostly single cells was discarded, and the pellets were transferred to non-treated petri dishes. With the aid of a dissecting microscope, all naked oocytes, cumulus oocytecomplexes (COCs), and debris were removed from the aspirate and washed twice in PBS. The sediment was collected into a centrifuge tube and washed several times in PBS, with centrifugation between washes. An aliquot of resuspended cells was manually dissociated using a 1-ml syringe with a 23-gauge needle and counted using a hemocytometer to determine the cell density.

Granulosa cells were plated in DMEM and 10\% fetal bovine serum (FBS; Life Technologies, Carlsbad, CA) at a density of $3.5 \times 10^{7}$ in a T-25 tissue culture flask (Becton Dickinson and Co., Franklin Lakes, NJ) for $16 \mathrm{~h}$, to facilitate the attachment of the granulose cells to the bottom of the flask. Once cells were attached, the medium was replaced with fresh DMEM containing 10\% FBS and cultured for $24 \mathrm{~h}$ or $48 \mathrm{~h}$ at $37^{\circ} \mathrm{C}$ in a humidified atmosphere of $5 \% \mathrm{CO}_{2}$ and $95 \%$ air. Following this, $100 \mathrm{nM}$ of rapamycin solution was added to each well and the cells were incubated for $24 \mathrm{~h}$ at $37^{\circ} \mathrm{C}$ in a humidified atmosphere of $5 \% \mathrm{CO}_{2}$ and $95 \%$ air. After $48 \mathrm{~h}$ of culture, samples of both normal untreated cells and rapamycin-treated cells were collected for immunoassay.

\section{Cloning of MAP1LC3A CDNA}

The amino acid sequences of human LC3A (GenBank Accession No. AF276658) were used to search the porcine expressed sequence tag (EST) database at GenBank (http://www.ncbi. nlm. nih.gov). Three homologous EST clones were obtained and manually assembled into a contig. Two pairs of primers (named LC3A) were designed from this contig sequence and used for the cloning of porcine MAP1LCA cDNA by reverse transcription PCR (RT-PCR) of the total RNA from porcine ovary (see Table 1 for primers).

The PCR amplification conditions were as follows: 100 $\mathrm{ng} / \mu \mathrm{l}$ of reverse-transcribed cDNA was amplified in a $25 \mathrm{ul}$ volume containing $2.5 \mathrm{ul}$ of $10 \times$ PCR buffer, 1 ul of 2.5 mM dNTPs, $2 \mathrm{U}$ of Taq polymerase, and 1ul of the 10nM each specific primers. PCR amplifications were performed in a PTC-200 DNA Engine thermocycler (MJ Research, Waltham, MA) for 40 cycles of denaturation at $95^{\circ} \mathrm{C}$ for 35 $\mathrm{s}$, annealing at $60^{\circ} \mathrm{C}$ for $35 \mathrm{~s}$, extension at $72^{\circ} \mathrm{C}$ for $40 \mathrm{~s}$, followed by a final extension step at $72^{\circ} \mathrm{C}$ for $10 \mathrm{~min}$. Amplified PCR products were TA-cloned into a pGEM-T vector and sequenced using the BigDye terminator sequencing kit and the ABI377 sequencer (PerkinElmer Life Sciences, Boston, MA) according to the manufacturer's instructions. 


\begin{tabular}{|c|c|c|}
\hline Primer name & Sequence & Size \\
\hline \multicolumn{3}{|l|}{ CDNA cloning primers } \\
\hline GeneRacer 3'-primer & $5^{\prime} G C T G T C A A C G A T A C G C T A C G T A A C G 3^{\prime}$ & \\
\hline GeneRacer 3'-nested primer & $5^{\prime}$ CGCTACGTAACGGCATGACAGTG $3^{\prime}$ & \\
\hline GeneRacer 5'-primer & $5^{\prime} C G A C T G G A G C A C G A G G A C A C T G A 3^{\prime}$ & \\
\hline GeneRacer 5'-nested primer & $5^{\prime} G G A C A C T G A C A T G G A C T G A A G G A G T A 3^{\prime}$ & \\
\hline $5^{\prime} R A C E-R v$ primer 1 & 5'TGTCCAGGACTGGCAGCTGCTTCT 3' & \\
\hline $5^{\prime}$ RACE-Rv primer 2 & $5^{\prime}$ CCAACTCGCTCATGTTGACATGGT $3^{\prime}$ & \\
\hline $3^{\prime}$ RACE-Fw primer & $5^{\prime}$ ATCGAGCGCTACAAGGGTGAGAAGC $3^{\prime}$ & \\
\hline \multicolumn{3}{|l|}{ Gene expression primers } \\
\hline Porcine GAPDH FW & $5^{\prime}$ CCCGTTCGACAGACAGCCGTG $3^{\prime}$ & 238 \\
\hline Porcine GAPDH Rv & $5^{\prime}$ CCGCCTTGACTGTGCCGTGG $3^{\prime}$ & \\
\hline Porcine MAPILC3A FW & $5^{\prime}$ AGAAGCAGCTGCCAGTCCTGGACA 3' & 687 \\
\hline Porcine MAPILC3A FW & $5^{\prime}$ CAGGCAGGCCTGAGCAATCTTTATT 3' & \\
\hline Porcine ATG5 FW & $5^{\prime}$ AGAGAAGTCTGTCCTTCCGCAGTCG $3^{\prime}$ & 241 \\
\hline Porcine ATG5 Rv & $5^{\prime}$ AAGCAGAAGGGTGACATGCTCTGGT $3^{\prime}$ & \\
\hline
\end{tabular}

\section{$5^{\prime}$ and $3^{\prime}$ RACE}

$5^{\prime}$ RACE was performed using a GeneRacer kit (Invitrogen). Total RNA was treated with calf intestinal phosphatase (CIP) to remove the $5^{\prime}$ phosphates to eliminate truncated mRNA from subsequent steps involving ligation with the GeneRacer RNA Oligo. Dephosphorylated RNA was then treated with tobacco acid pyrophosphatase (TAP) to remove the $5^{\prime}$ cap structure from the intact fulllength mRNA. This treatment leaves a $5^{\prime}$ phosphate, which is required for the ligation of the GeneRacer RNA Oligo to the $5^{\prime}$ end of the mRNA by using T4 RNA ligase. The $5^{\prime}$ RACE primers were designed according to the nucleotide sequence of a previous PCR product. A population of the mRNAs was transcribed into cDNA with an adaptor-primer containing a poly $(\mathrm{dT})$ tract at the $3^{\prime}$ end, and an arbitrary sequence of 30-40 nucleotides at the $5^{\prime}$ end. Followed by 2 successive $5^{\prime}$-RACE PCRs, elongated mRNA was reverse-transcribed into cDNA. $3^{\prime}$ RACE was performed using a GeneRacer Kit according to the manufacturer's instructions.

\section{In situ hybridization of MAP1LC3A mRNA}

Digoxigenin-labeled antisense and sense complementary MAP1LC3A RNA probes were prepared as previously described. Using recommended protocols, in situ hybridization was performed using a digoxigeninlabeled hybridization kit (Roshe, Mannheim, GER). For hybridization, ovarian tissues were sliced into $10-\mu \mathrm{m}$ sections. Digoxigenin-labeled probes $(200 \mathrm{ng} / \mathrm{ml})$ were hybridized to the ovarian tissue sections by using RiboHybe hybridization solution (TOYOBO, Osaka, JPN) at $65^{\circ} \mathrm{C}$ for $16 \mathrm{~h}$. Sections were washed in $2 \times \mathrm{SSC}$ for $5 \mathrm{~min}$ at $37^{\circ} \mathrm{C}$ and were fixed with $60 \%$ formamide in $0.2 \times$ SSC, which was applied 3 times for $5 \mathrm{~min}$ at $37^{\circ} \mathrm{C}$. After fixation, the sections were washed in $2 \times \mathrm{SSC}$ for $5 \mathrm{~min}$ at $37^{\circ} \mathrm{C}$. The probes were detected with an anti-digoxigenin antibody (1:200) in blocking solution and NBT/BCIP stock solution $(0.18 \mathrm{mg} / \mathrm{ml} \mathrm{BCIP}, 0.34 \mathrm{mg} / \mathrm{ml} \mathrm{NBT}$, and $240 \mu \mathrm{g} / \mathrm{ml} \mathrm{lev-}$ amisole). The samples were incubated for $16 \mathrm{~h}$ at room temperature. The slides were briefly dipped in fresh xylene, and a drop of permount (Fisher, PA) was then applied to the samples, which were finally covered with coverslips.

\section{Real-time PCR of MAP1LC3A and ATG5}

Total RNA was extracted from granulosa cell scrapings by using TRIzol reagent (Invitrogen, CA). The extracted product was treated with DNAse (Ambion, Austin, TX) as per the manufacturer's instructions and then quantified by UV spectrophotometry. First-strand cDNA synthesis was achieved by reverse transcription of mRNA by using an Oligo (dT) primer and SuperScript ${ }^{\mathrm{tm}}$ II Reverse Transcriptase (Invitrogen, Grand Island, NY). Real-time PCR using Line-gene K (Bioer Technology, Tokyo, JPN) was then performed in a final reaction volume of $25 \mu \mathrm{l}$ with SYBR Green (TOYOBO, Osaka, JPN). The primers used for PCR are shown in Table 1. The PCR conditions were as follows: 10 min at $94^{\circ} \mathrm{C}$, followed by 39 cycles of $30 \mathrm{~s}$ at $94^{\circ} \mathrm{C}, 30 \mathrm{~s}$ at $60^{\circ} \mathrm{C}$ or $65^{\circ} \mathrm{C}, 55 \mathrm{~s}$ at $72^{\circ} \mathrm{C}$, and a final extension step of 5 min at $72^{\circ} \mathrm{C}$. Rotor-Gene Real-Time Software 6.0 was used to analyze the results by using a cycle threshold $(\mathrm{Ct})$ to assess the semi-log amplification plot. Finally, the relative gene expression was analyzed using the 2- $\Delta \Delta \mathrm{Ct}$ method normalized to porcine glyceraldehyde-3-phosphate dehydrogenase (GAPDH) mRNA levels [17].

\section{Western blot}

Approximately $30 \mu \mathrm{g}$ of protein was electrophoretically separated in duplicate on a $13 \%$ gel by sodium dodecyl sulfate-polyacrylamide gel electrophoresis (SDS-PAGE), and transferred onto an immunoblot PVDF membrane (Bio-Rad). The membrane was incubated in blocking buffer ( $5 \%$ non-fat dry milk) overnight at $4^{\circ} \mathrm{C}$ and washed 3 times every $10 \mathrm{~min}$ with washing buffer $(0.1 \%$ $\mathrm{v} / \mathrm{v}$ Tween 20, $50 \mathrm{mM}$ Tris- $\mathrm{HCl} \mathrm{pH} \mathrm{7.6,} \mathrm{and} 200 \mathrm{mM}$ $\mathrm{NaCl}$ ). The membrane was then incubated for $2 \mathrm{~h}$ with anti-rabbit MAP1LC3A monoclonal antibody (diluted 1:1000; Abcam, MA), anti-rabbit ATG5 polyclonal antibody (diluted 1:1000; Abfrontier, Seoul, Kor). Following this, the membranes were washed 3 times for $15 \mathrm{~min}$, with $1 \times$ TBS-T buffer, and then incubated for $2 \mathrm{~h}$ with HRP-conjugated anti-rabbit and anti-mouse secondary antibodies (diluted 1:5000). The membrane was then developed in a dark room following exposure for $5 \mathrm{~min}$ with the detection reagent from an ECL-detection kit. The detection reagent was drained off and the 


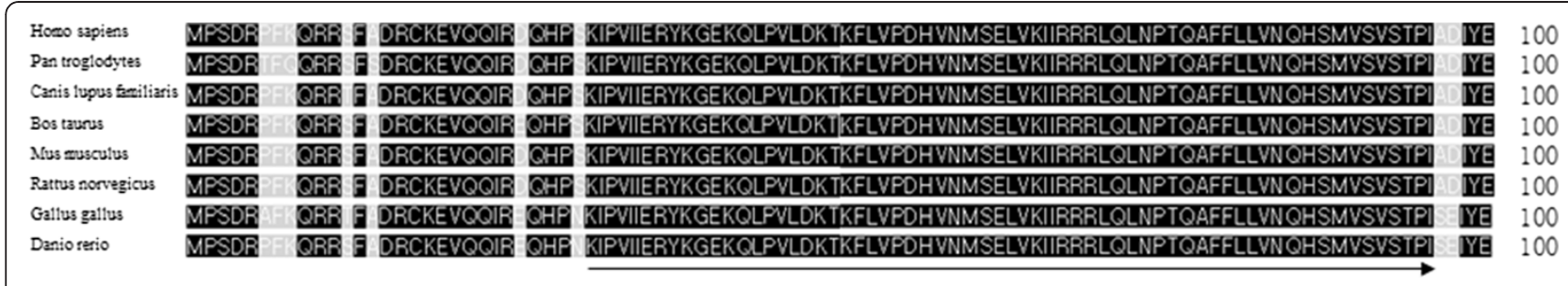

\begin{tabular}{|c|c|}
\hline FKnORA: & \\
\hline QEKDEDGFLYMVYASQETF & \\
\hline QEKDODGFLYMVYASQE & \\
\hline QEKDEDGFLYMVYASOETT & \\
\hline QEKDEDGFLYMVYASQETFG & \\
\hline QEKDEDGFLYMVYASQETFG & \\
\hline QEK & \\
\hline SERD & \\
\hline
\end{tabular}

Figure 1 Amino acid sequence comparison of mammalian MAP1LC3 proteins. Proteins used for alignments were from Homo sapiens (NP_115903.1); Pan troglodytes (XP_001159668.1); Canis lupus familiaris (XP_534391.2); Bos taurus (NP_001039640.1); Mus musculus (NP_080011.1); Rattus norvegicus (NP_955794.1); Gallus gallus (XP_417327.2); and Danio rerio (NP_999904.1). Identical residues are shaded in black, and similar residues are shaded in gray. Arrows indicate the primers used for cloning pig homologs.

membrane was exposed with a sheet of diagnostic film in the film cassette for 1-30 min.

\section{Detection of the MAP1LC3A and ATG5 by} immunofluorescence

Immunodetection of MAP1LC3A and ATG5 was performed on granulosa cells mounted on silanized slides.
Granulosa cells were cultured on sterilized glass coverslips, fixed with $4 \%$ paraformaldehyde, and blocked with $0.1 \%$ BSA in PBS. Slides were then incubated with monoclonal antibodies that specifically recognize the active forms of MAP1LC3A and ATG5 at a 1:150 dilution. After washing, the slides were incubated with an anti-rabbit IgG conjugated to Alexa 488 or Alexa 594 (Molecular Probes, Eugene, OR).

A 1 GTIACCTCCC CGAGCCGCOG COGCTGGGCT CAGCGCGAGC CCCAGAGCCC TIGAGCGGGA GACGCGGAGC COCOGGAGCC 80 81 COCAAACCAC AGCCACCTCC COGCCTCGCG CGACCGGGAG CCCOGGCCTG CGCGCTCOGC CGGGCCTGTG CGATOCCCTC 160 II P S 161 AGACCGGCCT TTCAAGCAGC GGCGGAGCTT CGCCGACCGC CGTAAGGAGG TGCAGCAGAT CCGCGACCAG CACOCTAGCA 240 $\begin{array}{llllllllllllllllllllllllllllllllll}D & R & P & F & K & Q & R & R & S & F & A & D & R & R & K & E & V & Q & Q & I & R & D & Q & H & P & S\end{array}$ 241 AGATCCCGGT GATCATCGAG CGCTACAAGG GTGAGAAGCA GCTGCCAGTC CTGGACAAGA CCAAGTTCCT GGTCCCAGAC 320

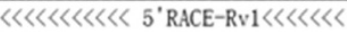
$<<$

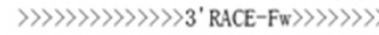

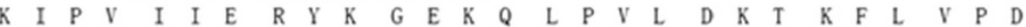
321 CATGTCAACA TGAGCGAGT GGTCAAGATC ATCCGGCGCC GCCTGCAGCT GAACCCCACG CAGGCCTTCT TOCTGCTGGT 400

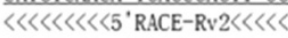

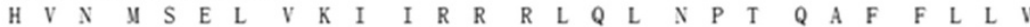
401 GAACCAGCAC AGCATGGTGA GCGTGTCCAC GCCCATCGCG GACATCTATG AGCAGGAGAA GGATGAGGAT GGCTTCCTCT 480

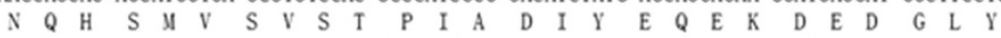
481 ACATGGTCTA CGCCTCCCAG GAAACCTTCG GCTTCTGAGC CAGCAGTAGG GGGTGTTGGC TGGGAGTCGG GGGCCCTGTC 560

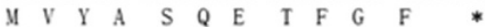

561 AGGCTCTGCC CAGGGAGCTC CTGGCACTGG AACTAAGCTG TCTCTGCOCC TGCOCCTGGT GGGTTGGACA GGGATGCTGC 640 641 CACCCAGCCA GAGGGCACCT ATCACOCCTA CTCTGCCCCT GGATGGATTC TGGCCCAGTC ATATTAGGGT TGCOCCTOCG 720 721 GGTGCTGGCT GGGAGGGGA AGAGTGGGAA GCAGCCCCCA GCACCCCTGC CCTGTGTGGT TTGTCTITIT TTTAGACCCC 800 801 TGCCTGTCTG CCCACCTGTC CCTCCOCAAC CTGAGGCGCT GCCCATGCCT GGATCTGCCC ACCCCTGAAG GACTGGGTCC 880 881 TGGCTCACCT GGTCTTGACA TGGTGTATGG CTCTGTGGTC ATTGTCCCTT TGCAGAATAA AGATTGCTCA GGCCTGCCTG 960 961 AAAAAAAAAA AAAAAAAAAA

B Human_LC3A MPSDRPFKQRRSFADRCKEVQQIRDQHPSKIPVIIERYKGEKQLPVLDKTKFLVPDHVNM Mouse_LC3A MPSDRPFKQRRSEADRCKEVQQIRDQHPSKIPVIIERYKGEKQLPVLDKTKELVPDHVNM Pig_LC $3 A$ MPSDRPFKQRRSFADRRKEVQQIRDQHPSKIPVIIERYKGEKQLPVLDKTKELVPDHVNM Bovine_LC3A MPSDRPFKQRRSFADRCKEVQQIREQHPSKIPVIIERYKGEKQLPVLDKTKELVPDHVNM SELVKIIRRRLQLNPT QAFFLLVNQHSMVSVST PIADIYEQEKDE DGFLYMVYASQETFG SELVKIIRRRLQLNPTQAFFLLVNQH SMVSVSTPIADIYEQEKDEDGFLYMVYASQETF SELVKI IRRRLQLNPTQAFFL LVNQH SMVSVST PIADIYEQEKDEDGFLYMVYASQETFC SELVKIIRRRLQLNPTQAFELLVNQHSMVSVSTPIADIYEQEKDEDGFLYMVYASQETFG

121

121

121

121

Figure 2 Full-length CDNA and ORF of porcine MAP1LC3A. A. Full-length CDNA and ORF of porcine MAP1LC3A. B. Comparison of the deduced amino acid sequences of the MAP1LC3A ORF with known mammalian proteins. 
Nuclei were counter-stained with $1 \mathrm{ug} / \mathrm{ml}$ Hoechst 33258, and slides were treated with fluorescent mounting medium (Dako, Carpinteria, CA). Images were acquired using an Olympus AX70 fluorescence microscope fitted with a CCD color camera.

\section{Statistical analysis}

Data were analyzed using the $t$-test with the Statistical Analysis System software (SAS Institute, version 9.4, Cary, NC). Differences among the treatment means were determined using Duncan's multiple range tests.

\section{Results}

\section{Cloning of the full-length porcine MAP1LC3A gene}

To design the primers for cloning the porcine MAP1LC3A gene, we compared the nucleotide sequence of homologous genes that have been identified in other vertebrates, such as humans, dog, cow, mouse, rat, chicken, and the zebra fish, in a multiplex alignment (Figure 1). PCR primers were designed to encompass the most conserved region between Lys (K)-30 and Ile (I)-95. PCR amplification using these primers produced a 710-bp fragment of porcine cDNA. The rest of the gene was obtained by $5^{\prime}$ and 3 -RACE, which were combined together to generate a 980-bp full-length sequence with an open reading frame of 121 amino acids. We found that the deduced amino acid sequence showed over $98 \%$ homology to the human, mouse, and cow proteins. In the regions upstream of Gly120 at the C-terminus, porcine MAP1LC3A was $100 \%$ identical to those of other mammals with an exception of some residue variation at Cys-16, which was replaced by Arg in humans, mouse, and cow. Such a high degree of structural homology strongly suggested that this newly cloned protein would perform the same function as the known mammalian MAP1LC3As, and was thus named as porcine MAP1LC3A (Figure 2). The sequence information of both cDNA and amino acids has been deposited in the GenBank (No. GU272221).

\section{Expression of MAP1LC3A in porcine follicles}

The expression of MAP1LC3A mRNA was examined by in situ hybridization in the Graafian follicles of pigs and miniature pigs at day 15 of the estrus cycle. Normal pigs exhibited higher levels of MAP1LC3A mRNA in the Graafian follicles than miniature pigs (Figure 3). The site of expression was also different between the 2 species. Although MAP1LC3A mRNA was more strongly expressed in the theca cell area of normal pigs than in that of miniature pigs, the expression was lower in the granulosa cells (Figure 3A). A higher expression of MAP1LC3A was also confirmed through conventional RT-PCR as well as through real-time PCR analyses of 4 animals from each group (Figure 3B). Therefore, MAP1LC3A was more abundant in the theca interna layer, which undergoes

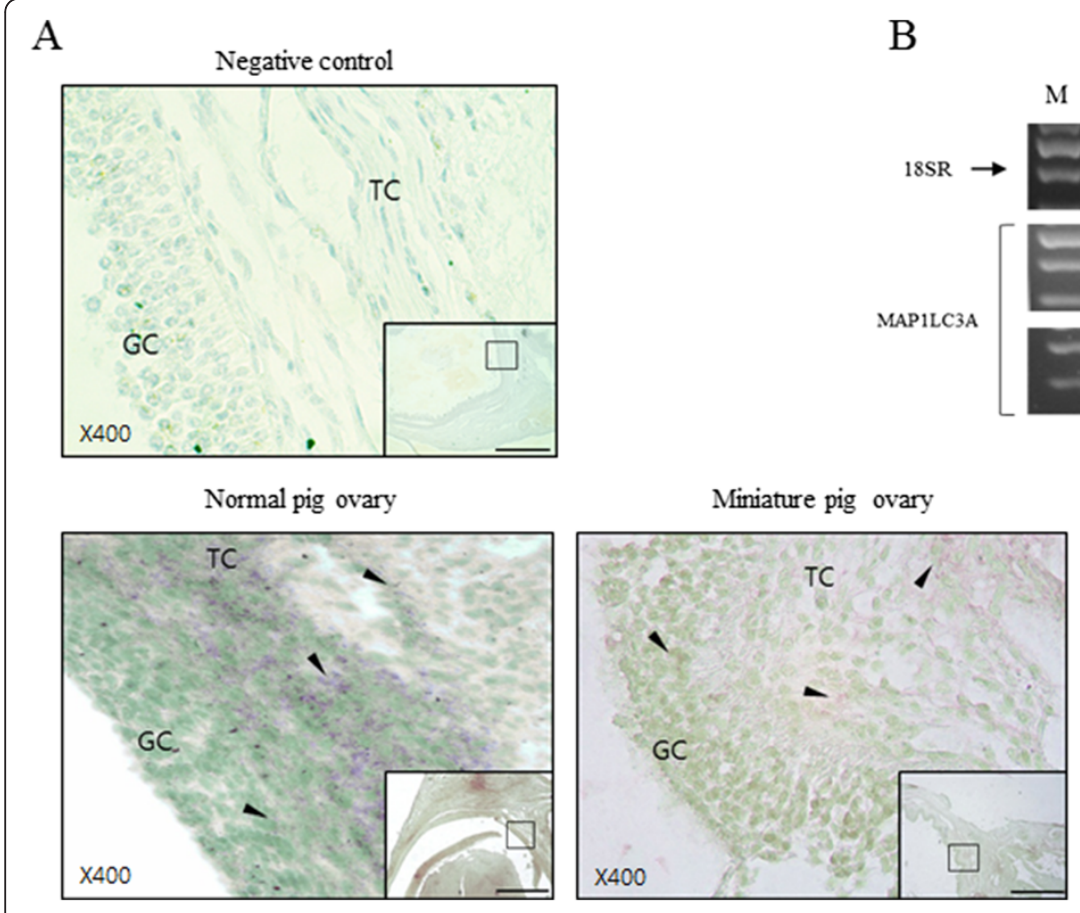

Figure 3 In situ detection and expression analyses of MAP1LC3A mRNA in the ovary. A. In situ hybridization of MAP1LC3A mRNA in the Graafian follicle of normal and miniature pigs. Arrows indicate positive cells. GC: granulosa cells; TC: theca cells. Prehybridization solution was used as the control for the Graafian follicle below the negative panel. B. Reverse transcription PCR and C. Real-time PCR of total RNAs from normal and miniature pig ovaries. Experiments were repeated 3 times, and data are expressed as mean \pm standard error ( $p<0.05$ ). Black bar $=100$ um in all figures. 
substantial remodeling through the processes of follicular development and expansion, than it was in the granulosa cell wall.

\section{Expression pattern of autophagy marker proteins in follicular cells}

Next, we examined the effect of rapamycin treatment on the expression of the autophagy marker proteins, MAP1LC3A and ATG5, in the follicular cells of pigs and miniature pigs. Granulosa cells exhibited an intrinsically higher expression of both markers, but this expression was even more enhanced upon rapamycin treatment (Figure 4). When the expression levels were compared between pigs and miniature pigs, marker expression was higher in normal pigs in the presence and in the absence of rapamycin (Figure 4A). We also assessed the changes in the expression of LC3 subtypes by western blot analysis (Figure 4B). In miniature pig granulosa cells, rapamycin elevated both LC3A-I and LC3A-II levels compared to those in the non-treated controls. Treating the granulosa cells of normal pigs with rapamycin resulted in an increase in LC3A-I but it actually lowered the expression of LC3A-II, probably due to the inherently robust expression of LC3A-II in pigs. Granulosa cells expression of ATG5 in normal pigs was higher than that in miniature pig cells, which was highly induced by rapamycin treatment. The changes and differences in the expression of these marker proteins were well reflected in the analyses of the corresponding mRNAs (Figure 4C).

\section{Discussion}

Autophagy is known to affect the process of development by enabling the remodeling of tissues and cells. A certain level of autophagy is essential for the maintenance of cellular survival and homeostasis [2,3]. The importance of appropriately initiated autophagy is particularly emphasized in the process of mammalian follicular development. The close association of apoptosis with folliculogenesis has been extensively studied [6,18]; however, a great paucity in the knowledge concerning the role of autophagy during porcine follicular development remains. It is well known that miniature pigs are distinct from normal pigs in many aspects of follicular development, as well as in the mode of ovulation and luteinization. Many of these distinctions between the 2 species are believed to arise from genetic differences in the factors governing the process of female reproduction $[19,20]$.

During oocyte development, the ovarian follicles undergo repeated remodeling, and they eventually regress into the

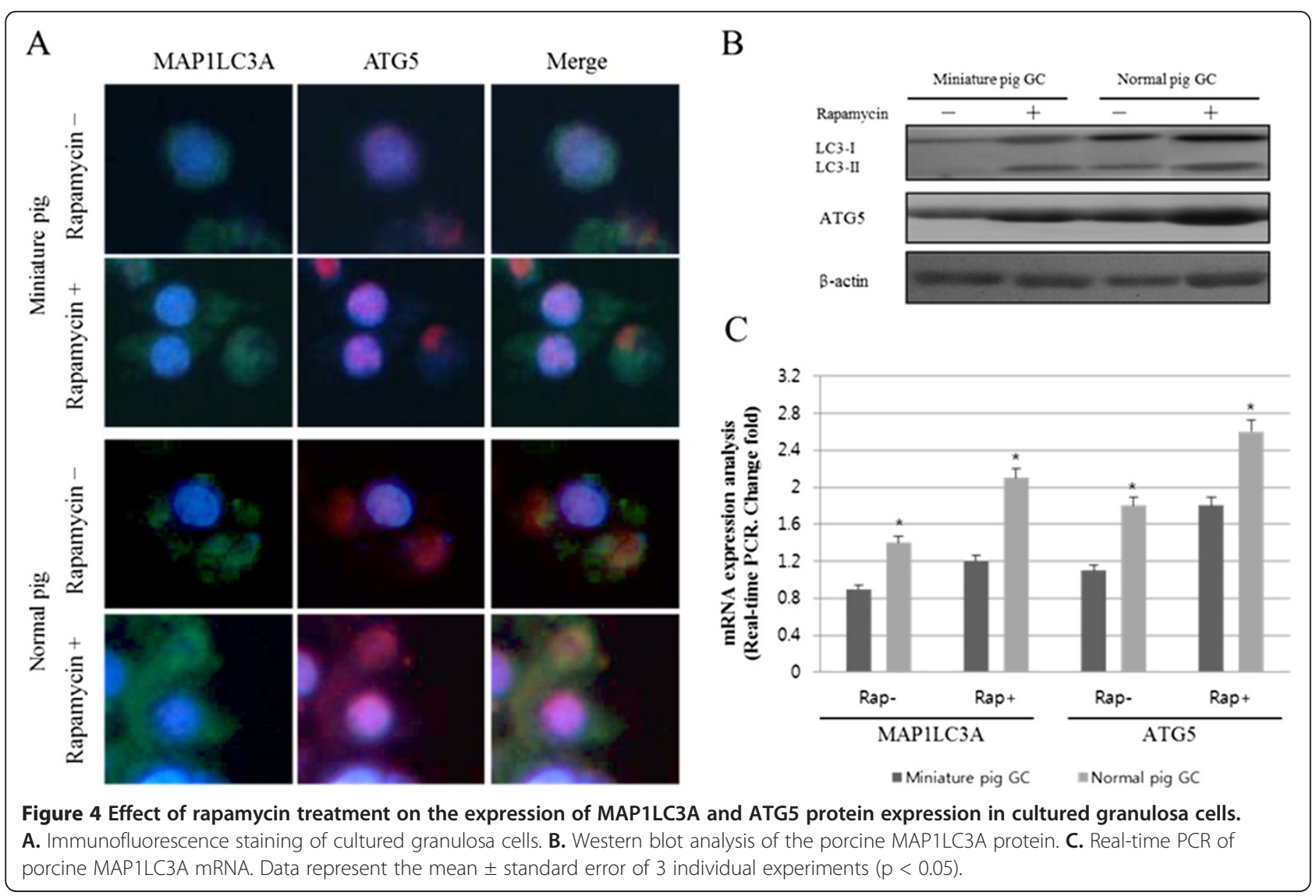


corpus luteum where they disintegrate through apoptosis $[21,22]$. According to a recent report, autophagy appears to serve as a major mechanism for the disintegration of dying follicles [5]. To this end, the distinct pattern of MAP1LC3A that we observed in miniature pig follicles may provide a clue to understanding the unique pathway of folliculogenesis in this animal. For example, we observed that MAP1LC3A was more abundant in the theca interna layer than it was in the granulosa cell wall. This result is reminiscent of a previous report by Duerrschmidt et al. (2006) which suggested that autophagy, as well as apoptosis, is involved in follicular development [18]. One intriguing fact in this report was that the expression pattern of autophagy markers in the Graafian follicles was different between pig and miniature pigs. Similar differences were also observed among cells cultured in vitro. Furthermore, treating the cells with rapamycin, a chemical inducer of autophagy, had a different effect on the expression of autophagy markers in the pig and miniature pig cells. Together, these results suggest that miniature pigs may employ a unique control of autophagy during follicular development, thereby indicating that pigs and miniature pigs are different in terms of their modes of reproduction [23-27]. A more detailed molecular analysis of the cellular signaling pathways controlling the process of autophagy will provide valuable information for improving the reproduction rates of miniature pig oocytes.

\section{Conclusions}

We report the first cloning of a full-length porcine MAP1LC3A gene. The open reading frame of porcine MAP1LC3A cDNA consists of 980 bp (encoding 121 amino acids). Based on its homology to known mammalian proteins (98\%) this novel cDNA was designated as porcine MAP1LC3A and registered to the GenBank (Accession No. GU272221). In addition, the expressions of MAP1LC3A and ATG5 were higher in normal pigs than in miniature pigs in the presence and in the absence of rapamycin. These results indicate that MAP1LC3A can be used as an autophagosomal marker in porcine follicular cells. Based on the expression of this novel marker protein, we propose that autophagy plays a role in the maintenance of follicular development at least partially by regulating the remodeling system in porcine follicular cells.

\section{Competing interests}

The authors declare that they have no competing interests.

\section{Authors' contributions}

SHK performed the experiments. SHK and SYH performed IHC. SHK and SYH drafted the manuscript. SHK, SYH, KSM, and JTY designed the study, supervised the experimental work, and revised the manuscript. These authors contributed equally to this paper. All authors read and approved the final manuscript.

\section{Acknowledgements}

The authors thank Dr. MS Lee (Medi Kinetics Co., Ltd) for their helpful discussions and to Dr. JK Jung for him technical assistance. This work was supported by BioGreen 21 Program (No.PJ009596), Rural Development Administation, and Technology Development program for Agriculture (No.109188-3), Ministry for Food, Agriculture, Forestry and Fisheries, Republic of Korea.

\section{Author details}

${ }^{1}$ Institute of Genetic Engineering, Hankyong National University, Ansung 456-749, Korea. ${ }^{2}$ Graduate School of Bio \& Information Technology, Hankyong National University, Ansung 456-749, Korea. ${ }^{3}$ Department of Animal Life Science, Hankyong National University, Ansung 456-749, Korea.

Received: 29 August 2012 Accepted: 8 December 2012

Published: 12 February 2013

\section{References}

1. Hershko A, Ciechanover A: The ubiquitin system. Annu Rev Biochem 1998, 67:425-479.

2. Petiot A, Ogier-Denis E, Blommaart EF, Meijer AJ, Codogno P: Distinct classes of phosphatidylinositol 3/-kinases are involved in signaling pathways that control macroautophagy in HT-29 cells. J Biol Chem 2000, 275:992-998.

3. Levine B, Klionsky DJ: Development by self-digestion: Molecular mechanisms and biological functions of autophagy. De Cell 2004, 6:6463-6477.

4. Tsukada M, Ohsumi Y: Isolation and characterization of autophagy defective mutants of Saccharomyces cerevisiae. FEBS Lett 1993, 333:169-174.

5. Choi JY, Jo MW, Lee EY, Yoon BK, Choi DS: The role of autophagy in follicular development and atresia in rat granulosa cells. Fertil Steril 2010, 93:2532-2537.

6. Billig H, Furuta I, Hsueh AJW: Estrogens inhibit and androgens enhance ovarian granulosa cell apoptosis. Endocrinology 1993, 133:2204-2212.

7. Mizushima N: Methods for monitoring autophagy. J Biochem Cell Biol 2004, 36:2491-2502

8. Pattingre S, Tassa A, Qu X, Garuti R, Liang XH, Mizushima N, Packer M, Schneider MD, Levine B: BCl-2 antiapoptotic proteins inhibit Beclin 1dependent autophagy. Cell 2005, 122:927-939.

9. Maiuri MC, Criollo A, Tasdemir E, Vicencio JM, Tajeddine N, Hickman JA, Geneste O, Kroemer G: BH3-only proteins and BH3 mimetics induce autophagy by competitively disrupting the interaction between beclin 1 and BCl-2/BCl-X(L). Autophagy 2007, 3:374-376.

10. Maiuri MC, Toumelin GL, Criollo A, Rain JC, Gautier F, Juin P, Tasdemir E, Pierron G, Troulinaki K, Tavernarakis N, Hickman JA, Geneste O, Kroemer G: Functional and physical interaction between $\mathrm{BCl}-\mathrm{X}(\mathrm{L})$ and a $\mathrm{BH}$-like domain in Beclin-1. EMBO J 2007, 26:72527-72539.

11. Xie Z, Klionsky DJ: Autophagosome formation: core machinery and adaptations. Nat Cell Bio 2007, 9:1102-1109.

12. He H, Dang Y, Dai F, Guo Z, Wu J, She X, Pei Y, Chen Y, Ling W, Wu C, Zhao S, Liu JO, Yu L: Post-translational modifications of three members of the human MAP1LC3 family and detection of a novel type of modification for MAP1LC3B. J Biol Chem 2003, 278:29278-29287.

13. Wu J, Dang Y, Su W, Liu C, Ma H, Shan Y, Pei Y, Wan B, Guo J, Yu L: Molecular cloning and characterization of rat LC3A and LC3B-two novel markers of autophagosome. Biochem Biophys Res Commun 2006, 339(1):437-442.

14. Fengsrud M: Lunde Sneve M, Overbye A, Seglen PO: Structural aspects of mammalian autophagy. In Autophagy. Edited by Klionsky DJ. Georgetown, TX: Landes Bioscience; 2004:11-25.

15. Juhasz G, Neufeld TP: Autophagy: a forty-year search for a missing membrane source. PLoS Biol 2006, 4:e36.

16. Mizushima N, Yamamoto A, Hatano M, Kobayashi Y, Kabeya Y, Suzuki K, Tokuhisa T, Ohsumi Y, Yoshimori T: Dissection of autophagosome formation using Apg5-deficient mouse embryonic stem cells. J Cell Biol 2001, 152:657-667.

17. Schmittgen TD, Livak KJ: Analyzing real-time PCR data by the comparative C(T) method. Nat Protoc 2008, 3:1101-1108.

18. Duerrschmidt N, Zabirnyk O, Nowicki M, Ricken A, Hmeidan FA, Blumenauer V, Borlak J, Spanel-Borowski K: Lectin-like oxidized low-density lipoprotein 
receptor-1-mediated autophagy in human granulosa cells as an alternative of programmed cell death. Endocrinology 2006, 147:3851-3860.

19. Howard PK, Chakraborty PK, Camp JC, Stuart LD, Wildt DE: Correlates of ovary morphology, estrous behavior and eyclicity in an inbred strain of miniature swine. Anat Rec 1982, 203:55-65.

20. Dor FJ, Tseng YL, Cheng J, Moran K, Sanderson TM, Lancos CJ, Shimizu A, Yamade K, Awwad M, Sachs DH, Hawley RJ, Schuurman HJ, Cooper DK: Alpha 1,3-galactosyltransferase gene-knockout miniature swine produce natural cytotoxic antiGal antibodies. Transplantation 2004, 78:15-20.

21. Hirshfield AN: Development of follicles in the mammalian ovary. Int Rev Cytol 1991, 124:43-101.

22. McGee EA, Hsueh AJ: Initial and cyclic recruitment of ovarian follicles. Endocr Rev 2000, 21:200-214.

23. Hughes FMJ, Gorospe WC: Biochemical identification of apoptosis (programmed cell death) in granulosa cell: evidence for a potential mechanism underlying follicular atresia. Endocrinology 1991, 129:2415-2422.

24. Byskov AGS: Atresia: Ovarian follicular development and function. In Edited by Midgley AR, Sadler WA. New York: Raven Press; 1979:41-57.

25. Guthrie HD, Cooper BS, Welch GR, Zakaria AD, Johnson LA: Atresia in follicles grown after ovulation in the pig: measurement of increased apoptosis in granulosa cells and reduced follicular fluid estradiol-17 $\beta$. Biol Reprod 1995, 52:920-927.

26. Guthrie HD, Grimes RW, Cooper BS, Hammond JM: Follicular atresia in pigs: measurement and physiology. J Anim Sci 1995, 73:2834-2844.

27. Tilly JL: Ovarian follicular atresia: a model to study the mechanisms of physiological cell death. Endocrinol J 1993, 1:67-72.

doi:10.1186/1477-7827-11-8

Cite this article as: Kim et al:: Molecular cloning and expression analyses of porcine MAP1LC3A in the granulosa cells of normal and miniature pig. Reproductive Biology and Endocrinology 2013 11:8.

\section{Submit your next manuscript to BioMed Central and take full advantage of:}

- Convenient online submission

- Thorough peer review

- No space constraints or color figure charges

- Immediate publication on acceptance

- Inclusion in PubMed, CAS, Scopus and Google Scholar

- Research which is freely available for redistribution 